HEALTH ECONOMICS

Health Econ. 24: 224-237 (2015)

Published online 5 November 2013 in Wiley Online Library (wileyonlinelibrary.com). DOI: 10.1002/hec.3012

\title{
INFORMAL CARE AND CAREGIVER'S HEALTH
}

\author{
YOUNG KYUNG DO ${ }^{\mathrm{a}, *}$, EDWARD C. NORTON ${ }^{\mathrm{b}}$, SALLY C. STEARNS ${ }^{\mathrm{c}}$ \\ and COURTNEY HAROLD VAN HOUTVEN ${ }^{\mathrm{d}}$ \\ ${ }^{\mathrm{a}}$ Department of Health Policy and Management, Seoul National University College of Medicine, and Institute of Health Policy and \\ Management, Seoul National University Medical Research Center, Seoul, Korea \\ ${ }^{\mathrm{b}}$ Department of Health Management and Policy \& Department of Economics, University of Michigan and NBER, Ann Arbor, MI, USA \\ ${ }^{\mathrm{c}}$ Department of Health Policy and Management, University of North Carolina at Chapel Hill, Chapel Hill, NC, USA \\ ${ }^{\mathrm{d}}$ Center for Health Services Research in Primary Care, Durham Veterans Affairs Medical Center, Department of Medicine, \\ Duke University Medical Center, Durham, NC, USA
}

\begin{abstract}
This study aims to measure the causal effect of informal caregiving on the health and health care use of women who are caregivers, using instrumental variables. We use data from South Korea, where daughters and daughters-in-law are the prevalent source of caregivers for frail elderly parents and parents-in-law. A key insight of our instrumental variable approach is that having a parent-in-law with functional limitations increases the probability of providing informal care to that parent-in-law, but a parent-in-law's functional limitation does not directly affect the daughter-in-law's health. We compare results for the daughter-in-law and daughter samples to check the assumption of the excludability of the instruments for the daughter sample. Our results show that providing informal care has significant adverse effects along multiple dimensions of health for daughter-in-law and daughter caregivers in South Korea. Copyright @ 2013 John Wiley \& Sons, Ltd.
\end{abstract}

Received 3 July 2012; Revised 23 September 2013; Accepted 7 October 2013

JEL Classification: D10; I10

KEY WORDS: informal care; caregiver health; instrumental variable estimation; Korea

\section{INTRODUCTION}

Although much economic research on informal care focuses on the health and health care use of an elderly parent, informal care may also adversely affect the health of the caregiver. Several mechanisms may lead to this effect (Schulz et al., 1995). Caregiving can worsen health through increased emotional stress and physical strain. Caregiving also inevitably involves observing a loved one's decline and anticipatory bereavement, which itself may affect the caregiver's health (Bobinac et al., 2010; Amirkhanyan and Wolf, 2006). Through these negative health effects, caregiving may increase a caregiver's health care use.

The provision of informal care may, however, be endogenous to caregivers' health, making the modeling of the endogeneity problem important to uncover the true effect (Coe and Van Houtven, 2009). Health status may affect the individual and family decisions on who provides informal care ('selection in') as well as whether the caregiver continues or ceases caregiving ('selection out') (Coe and Van Houtven, 2009). The selection criteria may not be monotonic in health. Although a healthier family member is more likely to take up the caregiving role because of the burdensome nature of caregiving, it is also possible that a less healthy or less productive family member may choose to provide informal care instead of participating in paid employment. Selection out may arise when

\footnotetext{
*Correspondence to: Department of Health Policy and Management, Seoul National University College of Medicine, 103 Daehak-ro,
} Jongno-gu, Seoul 110-799, Korea. E-mail: ykdo89@snu.ac.kr 
less healthy caregivers are more likely to stop providing informal care. This endogeneity issue makes it difficult to untangle the causal effect of informal caregiving on caregivers' health in observational data.

This study aims to measure the causal effect of caregiving on caregivers' health and health care use, using instrumental variables (IVs). We use nationally representative data from South Korea, where daughters and daughters-in-law are the prevalent source of caregivers for frail elderly parents and parents-in-law. A key insight is that having a parent-in-law with one or more activity of daily living (ADL) limitations increases the probability of providing informal care to that parent-in-law, but a parent-in-law's ADL limitation does not directly affect the daughter-in-law's health. We focus, therefore, on daughter-in-law caregivers and use the health of their parents-in-law as our instruments. We begin with a simple Wald estimator and perform careful robustness and falsification tests of the instruments to show that our instruments are theoretically and empirically valid in their application to informal caregiving in South Korea.

This paper makes several contributions to the empirical literature on caregiver health. First, we estimate the causal effect of caregiving on the health of the caregiver, controlling for the endogeneity between informal care and health using empirically strong IVs. Second, we estimate how caregiving affects a caregiver's own health care use and expenditures to provide policy-relevant information about how the health effects of caregiving may translate to public health care costs in an aging society. Third, we use data from South Korea, which has a unique cultural context about filial duty and caregiving as well as an emerging strong market of publicly provided long-term care. The unique data source allows us to estimate caregiver health effects separately for daughters and daughters-in-law, the latter being an important source of informal care in South Korea. The comparison between daughters and daughters-in-law is interesting empirically.

We find that informal care has adverse effects on health and health care for daughter-in-law and daughter caregivers in South Korea. Caregiving has significant spillover effects to caregiver health care expenditures. For example, compared with their non-caregiving counterparts, caregiving daughters-in-law annually spend on average 47\% (\$94,000, approximately \$90) more out-of-pocket on their own outpatient costs among those who use any outpatient care.

\section{BACKGROUND}

A large body of research has found negative health effects of caregiving (for reviews and meta-analyses, see Schulz et al., 1990; Schulz et al., 1995; Walker et al., 1995; Bookwala et al., 2000; Yee and Schulz, 2000; DilworthAnderson et al., 2002; Pinquart and Sörensen, 2003; Vitaliano et al., 2003; Pinquart and Sörensen, 2006; Pinquart and Sörensen, 2007). Despite considerable differences in the study design and outcome measures examined, the literature finds that compared with non-caregivers, caregivers experience overall poorer psychological and physical health (Schulz et al., 1995; Pinquart and Sörensen, 2003; Vitaliano et al., 2003). Additional caregiving often involves physical effort, lifting other people, and doing physical chores. This effort can lead to physical pain and poor self-assessed health in the caregiver, which leads to demand for health care and prescription drugs. Out-of-pocket expenditures increase both for visits to providers and for prescription drugs.

The main empirical challenge of the literature on caregiver health effects has been that caregiving (or care intensity among caregivers) is potentially endogenous. In their critical review of the earlier literature, Barer and Johnson (1990) point out that much of the literature uses self-selected samples. Schulz (1990) also suggests that health status may determine who will provide informal care in the family. Although well acknowledged, this methodological challenge has not been adequately addressed in the caregiving literature, with one recent exception (Coe and Van Houtven, 2009). Coe and Van Houtven (2009) address the endogeneity of both selection in and selection out of caregiving using different sets of IVs. They use the death of a parent to instrument for selection out of caregiving and sibling and family characteristics to instrument for selection into caregiving. In their longitudinal study, they find no evidence of endogeneity for selecting into caregiving but do find evidence of endogeneity for selecting out of caregiving.

We extend the literature by taking into account the endogeneity of informal caregiving in the IV framework, using data from an Asian cultural setting-South Korea. South Korea provides a particularly interesting setting for our empirical work. Although South Korea has become one of the fastest aging societies in the world, its 
strong tradition of filial piety means caregiving for frail elderly parents is the responsibility of adult children. Informal caregiving for disabled parents is embedded as an inseparable component of old-age support in traditional Korean culture (Sung, 1990), as in other East Asian cultures (Hsu and Shyu, 2003; Yamamoto and Wallhagen, 1997). Filial piety, an essential element of Confucianism, served as the major principle for the everyday lives of ordinary people, helping to keep the family as well as society in harmony (Chee, 2000). In an agrarian society until the 1960s, the Korean extended family served as a production unit as well as a communal living unit. Traditional Korean extended families continued with the eldest son's marriage and intergenerational co-residence with his parents. An eldest son inherited a larger share of bequests than his siblings would, in the form of house, farming land, and other real estate assets. The disproportionately larger bequest to the eldest son implied that the eldest son assumed the greatest role in familial responsibilities, which included co-residing with, supporting, and caring for elderly parents. The daughter-in-law married to the eldest son played a central role in familial responsibilities, including caring for ill and disabled parents. In a sense, the extended Korean family started with a designated future caregiver, the daughter-in-law, for aging parents (Choi, 1993).

Although the traditional form of parental caregiving is care by the eldest son's wife, recent decades have seen important changes in attitudes towards parental support. Eldest sons' wives now are less likely to assume their traditional role of parental caregiving than they were in the historically patrilineal society; at the same time, daughters increasingly play a greater role in caring for their own parents. Traditionally, daughters were viewed as leaving their family to join their husband's family after marriage, and therefore did not receive equal bequests from their own parents. A trend toward gender equality coupled with weakening traditional norms has changed this pattern. Therefore, when a woman has both parents and parents-in-law who need care, it is now less clear for whom she will provide care than in the past. Still, older women, especially those married to an eldest son, are more likely to uphold the traditional practice of daughters-in-law sharing the responsibility of caregiving in the husband's family. A younger woman who is the eldest daughter in her pre-marriage family and lives close by her parents tends to play an increasingly greater role in parental caregiving than in the past, suggesting potential heterogeneity among women who serve as caregivers to their parents or their parentsin-law. When faced with the competing demands for caregiver time (i.e., a woman has both a parent and a parent-in-law with limitations), the decision for whom a woman will provide care involves a more complex set of factors, including her birth order, her husband's birth order, the availability of substitutes (e.g., whether both parents-in-law are living together), and geographic proximity.

It is also less clear who should provide parental care in an extended family with several adult children. Economic theory suggests that the primary informal caregiver selected is more likely to be the one with the lowest opportunity cost of time, which in turn may be correlated with poorer health and other socioeconomic disadvantages. There is, however, a growing consensus among Koreans that 'more able' children, who have higher incomes and spacious houses, should take care of their parents. Formal long-term care is another option for families with disabled elderly parents. Because the introduction of public long-term care insurance in 2008, use of formal long-term care services has steadily increased, although it still remains relatively low compared with other developed countries, primarily due to the perceived low quality of institutional care overall and nonnegligible user fees among the poor. Home care (or 'in-house care') is also on the rise. Nevertheless, parental caregiving by daughters-in-law and daughters remains the major form of elderly long-term care in South Korea.

In this cultural and institutional context, functional limitations of elderly parents and in-laws can be a strong predictor of caregiving by daughters and daughters-in-law, and therefore a good source of instruments. However, parental care needs may have direct influences on adult children's psychological health (Amirkhanyan and Wolf, 2006). Having a functionally dependent parent may adversely affect the health of adult children, which is termed as 'the family effect' independent of 'the caregiving effect' (Bobinac et al., 2010). For example, an extra-residential daughter with a demented mother may still suffer psychological consequences even though she is not providing informal care to her mother. In the same vein, Amirkhanyan and Wolf (2003) distinguish non-caregiver stress from caregiver stress. Moreover, parents' functional limitations may also be correlated with adult children's (but not children-in-law's) health outcomes through 
genetic and behavioral similarities. For example, a 55-year-old daughter of an 85-year-old mother bedridden with stroke may share an increased susceptibility to many chronic diseases. There is less concern with instrument validity in models of physical health effects for the sample of daughters-in-law (where the instruments are functional limitations of parents-in-law, who obviously have no genetic link to the caregiver). The relatively high prevalence of caregiving by daughters-in-law in South Korea allows for studying daughterin-law caregivers separately from daughter caregivers.

The foregoing discussion provides a conceptual framework for a woman's caregiving decisions. Although the functional limitations of elderly parents and parents-in-law are the primary determinant of this decision, the availability of alternative sources of care, as well as location and the opportunity cost of time, is also likely to influence the decision process.

\section{METHODS}

We estimate several models to predict a woman's adverse health outcome or health care use $(y)$ as a function of whether she provides informal care to her parents (or parents-in-law) and other personal characteristics $(X)$.

$$
y=f(\text { Informal care }, X)
$$

The test of the main hypothesis is whether the coefficient on the informal care variable is statistically significant. We hypothesize that the coefficient on informal care will be positive, indicating that women who are informal caregivers have worse health and greater health care use. The goal is to obtain causal estimates of this relationship.

There are two main econometric issues. First, the dependent variables (health and health care use) are multifaceted, and therefore can be measured in several different ways. We estimate two models of health, and we estimate both extensive and intensive models of health care use and costs.

Second, informal care may be endogenous in a model that predicts health. Informal care is not provided randomly. The decision to provide informal care will depend in part on unobservable dimensions of health. Whether selection occurs in or out of caregiving, informal caregivers are likely selected, at least partially, based on health status. We need IVs to correct for the potential endogeneity of informal care. These instruments must be correlated with the decision to provide informal care but unrelated directly to the potential caregiver's health. We use indicators of any ADL limitations of the mother-in-law and of the father-in-law as two instruments for the sample of daughters-in-law. Having a parent-in-law with ADL limitations is highly predictive of providing informal care for that parent-in-law.

Counter examples are instructive. Infectious diseases can spread within families, but we are not measuring an infectious disease. Some health problems are inherited, but in-laws are not typically closely genetically related. Assortative mating could lead to a correlation in the health and health behaviors of daughters-in-law and parents-in-law; however, this link cannot be as strong as the link between daughters and parents. Although some women may develop strong emotional bonds with their in-laws, in general, the daughter-in-law will be less emotionally vested in the health decline of the parent-in-law. In short, we argue that a parent-in-law's health problems primarily affect a daughter-in-law's health through caregiving, rather than directly. The exclusion argument is harder to make for daughters caring for their parents due to heritability and closeness, but for completeness and comparison, we also estimate models with daughters as caregivers.

Before running the full IV models, we first obtain Wald estimators for each of our health outcome measures to show the plausibility of the proposed instruments and the rough estimate of the magnitude of the effect. The simple Wald estimator is calculated as follows (Angrist and Evans, 1998). Consider the following regression model.

$$
y=\alpha+\beta I C+\varepsilon
$$

where $y$ is a health outcome measure, and $I C$ is the endogenous binary variable of interest, whether the respondent provided any informal care. Let $\alpha$ be the constant term and $\beta$ be the coefficient of interest. The random 
error is $\varepsilon$. Now, we consider a binary instrument $(z)$ for the sample of daughters-in-law-whether either parentin-law has any ADL limitations ( $z=1$ if any ADL limitations, 0 if otherwise). The IV-Wald estimate of $\beta$ is the ratio of two differences. The numerator is the difference between the expected value of $y$ for those whose parents-in-law have ADL limitations $\left(\overline{y_{1}}\right)$ and for those whose parents-in-law do not have ADL limitations $\left(\overline{y_{0}}\right)$. The denominator is the difference between the expected value of informal care for those whose parents-inlaw have ADL limitations $\left(\overline{I C_{1}}\right)$ and for those whose parents-in-law do not have ADL limitations $\left(\overline{I C_{0}}\right)$. The estimate $\beta_{\text {IV-Wald }}$ is the average treatment effect of informal caregiving on a particular health outcome in question $(y)$ for the subgroup of individuals whose probability of providing informal care (IC) has been affected by having a parent-in-law with any ADL limitations $(z)$.

$$
\beta_{\text {IV-Wald }}=\frac{\left(\overline{y_{1}}-\overline{y_{0}}\right)}{\left(\overline{I C_{1}}-\overline{I C_{0}}\right)}
$$

In this sense, $\beta_{\text {IV-Wald }}$ can be interpreted as a local average treatment effect (Imbens and Angrist, 1994; Angrist et al., 1996; Angrist and Evans, 1998). Robust standard errors for these Wald estimators can be easily obtained by running regression models with the only endogenous explanatory variable of informal care for parent(s)-in-law and one IV of whether either parent-in-law has ADL limitations. In a similar way, we also calculate Wald estimators for the samples of daughters, using a different binary instrument of whether either mother or father has any ADL limitations.

As a next step, we conduct falsification tests of the Wald estimator by using the wrongly matched instrument for each sample; namely, using the instrument of whether either mother or father has any ADL limitations to predict the probability of providing informal care for parents-in-law for the sample of daughters-in-law, and using the instrument of whether either the mother-in-law or father-in-law has any ADL limitations to predict the probability of providing informal care for parents for the sample of daughters. The Wald estimators from these falsification tests should not produce sensible results.

We then estimate the full IV models controlling for other observable characteristics. These other characteristics include daughter(-in-law)'s age, education, wealth, home ownership, health insurance, and whether both parents(-in-law) are living together. In this step, we use two instruments for each sample, allowing for over-identification: whether the mother-in-law has any ADL limitations $\left(z_{1}\right)$ and whether the father-in-law has any ADL limitations $\left(z_{2}\right)$ for the sample of daughters-in-law, and whether the mother has any ADL limitations $\left(z_{1}\right)$ and whether the father has any ADL limitations $\left(z_{2}\right)$ for the sample of daughters. We use specification tests to assess the instrument validity and the exogeneity of the potentially endogenous variable of informal care.

Another potential method of dealing with endogeneity is to use longitudinal data and exploit within-individual variations while also possibly controlling for baseline health status (Coe and Van Houtven, 2009). Our data from South Korea have only three waves and thus have limited variation between waves in key variables. We estimated random-effects and fixed-effects models as well as models including lagged health variables but found most estimation methods show signs of insufficient variation and limited sample size, particularly for the models with a binary dependent variable. Given the data limitations, our preferred method is the IV model using repeated observations.

As a sensitivity test, we repeat our analysis using logged informal care hours instead of the indicator variable of informal caregiving and examine whether accounting for the extent of caregiving changes our main results. Because the results from the alternative specification remain largely similar, we present our results using the specification of the indicator variable of informal caregiving. Other results are available upon request.

\section{DATA}

This study uses data from the first three waves (2006, 2008, and 2010) of the Korean Longitudinal Study of Aging (KLoSA). The KLoSA is a nationally representative study of non-institutionalized South Korean adults aged 45 years or older in 15 large administrative areas. The KLoSA is designed to be comparable with aging 
panel studies from other regions, including the US Health and Retirement Study and the European Survey of Health and Retirement in Europe (Boo and Chang, 2006). The KLoSA contains detailed information on the respondents as well as their children, siblings, and parents. In its first wave, conducted in 2006, 10,254 individuals (5788 women) in 6171 households were interviewed face-to-face using the computer-assisted personal interviewing method. In the second (2008) and third (2010) waves, $84.7 \%$ and $77.2 \%$ of the original sample were respectively followed up without replacement.

We restrict our study sample to women with any living parents-in-law and women with any living parents, leaving 2531 observations in the daughter-in-law sample and 4110 observations in the daughter sample. Because information on parents-in-law can only be identified among currently married women in our data, the daughter-in-law sample is smaller in number than the daughter sample. There are 1348 observations with both 'any living parents-in-law' and 'any living parents'. After removing five observations with missing values for the study variables, our main statistical analysis uses the final daughter-in-law $(N=2528)$ and daughter $(N=4108)$ samples.

\subsection{Outcome variables}

Various outcome measures have been used to capture the effects of informal caregiving on psychological and physical health as well as on health care use and medication (Schulz, 1990; Haley et al., 1987; Pang, 2000; Yong and McCallion, 2003). In this study, we focus on physical health outcomes and health care use and costs, rather than psychological health outcomes, because of the concern that psychological outcomes are likely prone to the family effect (Bobinac et al., 2010).

First, we define a dichotomous variable indicating pain affecting daily activities. Caregiving often involves physical efforts and may produce physical pain. Moreover, individuals with psychological distress often present with physical symptoms, which is known as somatization (Pang, 2000). Although this argument for somatization may raise the concern that pain can result from the family effect, we believe this concern is lessened among daughter-in-law caregivers. Second, we construct a binary variable of fair to poor self-rated health to capture overall subjective health. Although additional health variables are available from the data, most of these variables are excluded because their psychological or disease-specific nature fails to meet two criteria: being able to capture physical health and being sufficiently generic.

Our health care use and costs variables are derived from information on outpatient care use and regular prescription drug use in the past 12 months. We define a binary indicator variable of any outpatient care use $=1$ if the respondent reported having visited a doctor's office and hospital outpatient office, including the emergency room, at least once in the past 12 months. For those with any outpatient care use, we create a continuous variable of the total out-of-pocket spending for outpatient care paid by the respondent during the same period. We also create two variables for regular prescription drug use in the same way as for outpatient care use: any regular prescription drug use and out-of-pocket spending for regular prescription drug use conditional on any use during the past 12 months. We focus on the use of outpatient care and prescription drugs, rather than inpatient care use and other types of health care use that may be limited in capturing the patient's overall health status. Although our measures of health care use and costs may reflect influences other than health status itself (e.g., insurance status and health-seeking behavior) and possibly pose concerns over the accuracy of reporting, we choose to use these measures because they are relatively objective, and they allow for summarizing multiple sources of the negative health effects of caregiving. In presenting the potential effect of caregiving on health care financing, the use of these measures becomes highly policy relevant. Because the distribution of out-of-pocket spending shows the typical right-skewed pattern, we tested for the most appropriate Box-Cox transformation and use the natural logarithm of these two cost variables.

\subsection{Explanatory variables}

The key explanatory variable is a binary indicator variable of any informal care provided to parents-in-law (daughter-in-law sample) or a binary variable of any informal care provided to parents (daughter sample). In 
the KLoSA, ADL care was asked regardless of co-residential status, but IADL care was only asked about care provided to non-co-residing parents(-in-law).

Our statistical models control for a set of demographic and socioeconomic factors, including age, education, home ownership, health insurance status, whether both parents(-in-law) are living together, type of residential area, and survey year. In South Korea, every Korean citizen is insured by either National Health Insurance or Medical Aid. Medical Aid, which is a public assistance program for the poor and other specified groups, has two types. Medical Aid type 1 is for the poorer among the poor and charges lower out-of-pocket costs than type 2. In addition to these statutory medical security programs, individuals can purchase supplemental voluntary private health insurance for protection from the financial burden of outof-pocket medical expenditures.

\section{RESULTS}

The main instrument is largely balanced across other covariates, providing evidence that the instrument is unlikely to be correlated with anything other than the probability of being a caregiver. Comparisons of the daughters-in-law by having at least one parent-in-law with ADL limitations (Table IA) show that the women are similar on all measured characteristics except age, home ownership and, of course, caregiver status. Women with at least one parent-in-law with ADL limitations are slightly older on average (55.3 versus 53.3 years old) and are more likely to own a home; $60.0 \%$ of these women provided informal care to their parents-in-law compared with only $0.2 \%$ (four out of 2433) of the women who had parents-in-law without ADL limitations. These four caregivers are non-residential caregivers who provided IADL care only. Thus, parent-in-law ADL limitations satisfy one criteria for a good instrument, namely that it be highly correlated with the potentially endogenous variable. The Wald estimators based on ADL limitations for at least one parent-inlaw show statistically significant adverse health effects $(p<0.1)$ in the outcome measures except for any outpatient care use and the log of out-of-pocket prescription drug costs, conditional on any regular prescription drug use (Table IB). The basic results also hold for the estimates that control for other covariates, as will be shown later.

Group comparisons and Wald estimators for the daughter sample show similar patterns (Table II), although daughters having parent(s) with ADL limitations are also less educated, more likely to be on the Medical Aid program, and are slightly older. Among daughters having parent(s) with any ADL limitations, 26.3\% provided informal care to their parent(s), whereas informal caregiving was reported by only $0.3 \%(=10 / 3850)$ of women whose parent(s) had no ADL limitations (last row of Table IIA). The Wald estimator for the difference in outcomes measures based on parental ADL limitations shows significant adverse effects $(p<0.05)$ for all outcome measures except the log of out-of-pocket prescription drug costs, conditional on any regular prescription drug use (Table IIB).

The falsification tests for the Wald estimators in Table III (based on the effect of parental ADL limitation on the probability of providing informal care for parents-in-law in the daughter-in-law sample and that of parent-in-law ADL limitation on the probability of providing informal care for parents in the daughter sample) show no statistically significant adverse health outcomes $(p<0.10)$, even suggesting beneficial effects. The estimated differences in outcomes are extremely large for many measures and have large standard errors. The erratic results from using a 'nonsensical' instrument for each sample, combined with the Wald estimators shown in Tables IB and IIB, suggest that the differential probabilities of providing parental care induced by conceptually appealing instruments (i.e., the presence of functionally dependent parents or parents-in-law for the corresponding sample of daughters or daughters-in-law) can be used to identify the estimated health effects of caregiving. Therefore, the main limitation of the Wald estimators in Tables IB and IIB is the fact that they are based only on the allocation into groups according to ADL status of parents (for the daughter sample) and parents-in-law (for the daughter-in-law sample) and do not adjust for any of the observed characteristics of the women. 
Table I. Summary statistics and Wald estimators in daughters-in-law $(N=2528)$

\begin{tabular}{|c|c|c|c|c|}
\hline Variable & $\begin{array}{c}\text { Parent(s)-in-law have no ADL } \\
\text { limitations }(n=2433)\end{array}$ & $\begin{array}{l}\text { Parent(s)-in-law have any } \\
\text { ADL limitations }(n=95)\end{array}$ & & \\
\hline Table IA: Daughter-in-law characteristics & Mean & Mean & $p$-value ${ }^{\dagger}$ & \\
\hline Age (year) & 53.29 & 55.31 & $<0.01$ & \\
\hline Education $(\%)$ & & & 0.21 & \\
\hline Elementary school or less & 24.58 & 27.37 & & \\
\hline Middle school & 20.72 & 25.26 & & \\
\hline High school & 44.43 & 43.16 & & \\
\hline College or more & 10.28 & 4.21 & & \\
\hline Home ownership (\%) & 83.26 & 92.63 & 0.02 & \\
\hline Statutory medical security (\%) & & & 0.52 & \\
\hline National Health Insurance & 98.31 & 96.84 & & \\
\hline Medical aid type 1 & 0.70 & 1.05 & & \\
\hline Medical aid type 2 & 0.99 & 2.11 & & \\
\hline Voluntary private health insurance & 56.39 & 52.63 & 0.47 & \\
\hline Both parents-in-law living together (\%) & 16.19 & 10.53 & 0.14 & \\
\hline Residential area (\%) & & & 0.40 & \\
\hline Metropolitan & 46.65 & 42.11 & & \\
\hline Small city & 34.57 & 33.68 & & \\
\hline Rural & 18.78 & 24.21 & & \\
\hline KLoSA wave $(\%)$ & & & 0.68 & \\
\hline Wave 1 (2006) & 41.10 & 41.05 & & \\
\hline Wave 2 (2008) & 32.22 & 35.79 & & \\
\hline Wave 3 (2010) & 26.67 & 23.16 & & \\
\hline Caregiving for a least one parent-in-law & 0.0016 & 0.6000 & - & \\
\hline Table IB: Wald estimator $r^{\dagger \dagger}$ & Mean & Mean & Wald & $(\text { S.E. })^{\dagger \dagger \dagger}$ \\
\hline Pain affecting daily activities & 0.14 & 0.26 & $0.20 * * *$ & $(0.08)$ \\
\hline Self-reported health fair to poor & 0.36 & 0.49 & $0.22 * *$ & $(0.09)$ \\
\hline Any outpatient care use & 0.62 & 0.60 & -0.03 & $(0.09)$ \\
\hline $\log ($ out-of-pocket costs) if any use & 1.81 & 2.13 & $0.55 * *$ & $(0.28)$ \\
\hline Any regular prescription drug use & 0.29 & 0.39 & $0.17 *$ & $(0.09)$ \\
\hline $\log$ (out-of-pocket costs) if any use & 2.96 & 3.14 & 0.25 & $(0.30)$ \\
\hline
\end{tabular}

ADL, activity of daily living; KLoSA, Korean Longitudinal Study of Aging.

${ }^{\dagger}$ Test statistics for $t$-test (continuous variable) or chi-sq test (categorical variable).

${ }^{\dagger}$ Table VA provides the number of observations used for each outcome measure.

${ }^{\dagger \dagger}$ Robust standard errors in parentheses.

$* p<0.1$. ** $p<0.05$. *** $p<0.01$.

The relatively high proportions of women (daughters or daughters-in-law) who respond to the corresponding instruments of ADL status (for parents or parents-in-law) by providing care, and the negligible proportion of women providing care for parents or parents-in-law without ADL limitations suggest that the instruments should have a strong predictive power in the first-stage regression (Angrist et al., 1996). Indeed, the indicators of ADL limitations among parents or parents-in-law are essentially the most important predictors of informal caregiving by daughters or daughters-in-law (Table IV), which is not surprising because those IVs are the reason for providing parental care. The $F$-test at the bottom of Table IV indicates that the instruments are strong ( $F$-statistics 86 and 37). In contrast, most other factors have small coefficients and fail to reach statistical significance at the $10 \%$ level. All else being equal, having both parents(-in-law) living together reduces the probability of a daughter(-in-law) providing care by 0.8 (1.4) percentage points, and these effects are statistically significant despite the small magnitude. The surprisingly small magnitude is likely reflected in the small proportion $(<20 \%)$ of daughters(-in-law) with both parents(-in-law) living together in our study sample (Tables I and II).

Table V provides the IV estimates of the effect of caregiving on health outcomes and the results from specification tests (for over-identification and exogeneity) for the separate samples of daughters-in-law and daughters. The tests for over-identification (column 8) show support for valid identification in all models. 
Table II. Summary statistics and Wald estimators among daughters $(N=4108)$

\begin{tabular}{|c|c|c|c|c|}
\hline Variable & $\begin{array}{l}\text { Parent(s) have no ADL } \\
\text { limitations }(n=3850)\end{array}$ & $\begin{array}{l}\text { Parent(s) have any ADL } \\
\text { limitations }(n=258)\end{array}$ & & \\
\hline Table IIA: Daughter characteristics & Mean & Mean & $p$-value ${ }^{\dagger}$ & \\
\hline Age (year) & 54.16 & 56.56 & $<0.01$ & \\
\hline Education (\%) & & & $<0.01$ & \\
\hline Elementary school or less & 27.58 & 41.86 & & \\
\hline Middle school & 21.74 & 19.77 & & \\
\hline High school & 40.52 & 31.01 & & \\
\hline College or more & 10.16 & 7.36 & & \\
\hline Home ownership (\%) & 81.17 & 78.29 & 0.26 & \\
\hline Statutory medical security $(\%)$ & & & 0.03 & \\
\hline National Health Insurance & 96.23 & 93.41 & & \\
\hline Medical aid type 1 & 1.64 & 3.88 & & \\
\hline Medical aid type 2 & 2.13 & 2.71 & & \\
\hline Voluntary private health insurance & 53.64 & 49.61 & 0.21 & \\
\hline Both parents living together $(\%)$ & 6.49 & 3.49 & 0.06 & \\
\hline Residential area (\%) & & & 0.21 & \\
\hline Metropolitan & 47.51 & 53.10 & & \\
\hline Small city & 34.39 & 30.23 & & \\
\hline Rural & 18.1 & 16.67 & & \\
\hline KLoSA wave (\%) & & & 0.11 & \\
\hline Wave 1 (2006) & 40.34 & 44.96 & & \\
\hline Wave 2 (2008) & 32.05 & 33.33 & & \\
\hline Wave 3 (2010) & 27.61 & 21.71 & & \\
\hline Caregiving for a least one parent & 0.0026 & 0.2636 & - & \\
\hline Table IIB: Wald estimator ${ }^{\dagger \dagger}$ & Mean & Mean & Wald & $(\text { S.E. })^{\dagger \dagger}$ \\
\hline Pain affecting daily activities & 0.17 & 0.37 & $0.75 * * *$ & $(0.16)$ \\
\hline Self-reported health fair to poor & 0.39 & 0.61 & $0.85 * * *$ & $(0.16)$ \\
\hline Any outpatient care use & 0.63 & 0.71 & $0.33 * * *$ & $(0.13)$ \\
\hline $\log$ (out-of-pocket costs) if any use & 1.85 & 2.08 & $0.92 * *$ & $(0.39)$ \\
\hline Any regular prescription drug use & 0.31 & 0.47 & $0.63 * * *$ & $(0.15)$ \\
\hline $\log$ (out-of-pocket costs) if any use & 2.88 & 2.98 & 0.43 & $(0.55)$ \\
\hline
\end{tabular}

ADL, activity of daily living; KLoSA, Korean Longitudinal Study of Aging.

${ }^{\dagger}$ Test statistics for $t$-test (continuous variable) or chi-sq test (categorical variable).

thable VB provides the number of observations used for each outcome measure.

${ }^{\dagger \dagger}$ Robust standard errors in parentheses.

$* p<0.1$. ** $p<0.05$. *** $p<0.01$.

The tests for exogeneity are more equivocal, with statistical evidence of endogeneity in five of the 12 models estimated.

For the daughter-in-law sample, the models show an adverse impact of caregiving on caregiver health for the following outcome measures ( $p<0.10$, the magnitude of effect in parenthesis): having pain affecting daily activities (13 percentage points), having fair or poor self-reported health (16 percentage points), and outof-pocket outpatient care costs if any use (47\%), although the specification test does not reject exogeneity of the IV-probit estimates.

For the daughter sample, the models show an adverse impact of caregiving on caregiver health for the following outcome measures ( $p<0.10$, the magnitude of effect in parenthesis): having pain affecting daily activities (41 percentage points), having fair or poor self-reported health (56 percentage points), having any outpatient care use (30 percentage points), out-of-pocket outpatient care costs if any use (75\%), and having any regular prescription drug use (34 percentage points).

No beneficial and statistically significant impacts on health outcomes from caregiving were estimated for any model, as expected. Therefore, although controlling for additional covariates in a full IV framework reduced the number of health measures with adverse impacts from caregiving, adverse impacts from caregiving appears to have occurred for a number of measures. We find that most of the coefficient 
Table III. Falsification test for Wald estimation in daughters-in-law and daughters

\begin{tabular}{|c|c|c|c|c|}
\hline $\begin{array}{l}\text { Sample } \\
\text { Potentially endogenous variable } \\
\text { Instrumental variable }\end{array}$ & $\begin{array}{r}\text { Daug } \\
\text { Caregiving } \\
\text { Parent has }\end{array}$ & $\begin{array}{l}N \\
\text {-in-law } \\
\text { tations }\end{array}$ & $\begin{array}{r}\text { Careg } \\
\text { Parent-in-lay }\end{array}$ & $\begin{array}{l}\text { at } \\
\text { nitations }\end{array}$ \\
\hline Outcome & Coefficients & $(\text { S.E. })^{\dagger}$ & Coefficients & $(\text { S.E. })^{\dagger}$ \\
\hline Prob (pain affecting daily activities) & 4.56 & $(5.88)$ & $-11.23 *$ & $(6.70)$ \\
\hline Prob (self-reported health fair to poor) & 8.19 & (11.15) & $-15.93 *$ & $(8.32)$ \\
\hline Prob (any outpatient care use) & 5.54 & $(8.09)$ & -3.87 & $(6.30)$ \\
\hline Log (out-of-pocket costs) if any use & 10.38 & $(12.58)$ & -40.84 & $(29.56)$ \\
\hline Prob (any regular prescription drug use) & 11.16 & $(15.11)$ & $-14.55^{*}$ & $(8.32)$ \\
\hline Log (out-of-pocket costs) if any use & 8.76 & (11.94) & -6.98 & $(18.45)$ \\
\hline
\end{tabular}

ADL, activity of daily living.

${ }^{\dagger}$ Robust standard errors in parentheses.

$* p<0.1$.

Table IV. First-stage regression of caregiving for parent-in-law and for parent

\begin{tabular}{|c|c|c|c|c|}
\hline \multirow[b]{2}{*}{ Variable } & \multicolumn{2}{|c|}{ Caregiving for parent-in-law by daughter-in-law } & \multicolumn{2}{|c|}{ Caregiving for parent by daughter } \\
\hline & Coefficients & $(\text { S.E. })^{\dagger}$ & Coefficients & $(\text { S.E. })^{\dagger}$ \\
\hline \multicolumn{5}{|l|}{ Instrumental variables } \\
\hline Father-in-law has ADL limitations & $0.3940 * * *$ & $(0.1067)$ & - & \\
\hline Mother-in-law has ADL limitations & $0.6178 * * *$ & $(0.0554)$ & - & \\
\hline Father has ADL limitations & - & & $0.2206 * * *$ & $(0.0644)$ \\
\hline Mother has ADL limitations & - & & $0.2564 * * *$ & $(0.0327)$ \\
\hline Age (year) & 0.0007 & $(0.0004)$ & -0.0003 & $(0.0003)$ \\
\hline \multicolumn{5}{|l|}{ Education } \\
\hline Elementary school or less & -0.0069 & $(0.0059)$ & 0.0016 & $(0.0067)$ \\
\hline Middle school & -0.0056 & $(0.0054)$ & 0.0086 & $(0.0063)$ \\
\hline High school & -0.0032 & $(0.0043)$ & 0.0060 & $(0.0056)$ \\
\hline College or more (ref.) & - & & - & \\
\hline Home ownership & -0.0023 & $(0.0064)$ & 0.0001 & $(0.0057)$ \\
\hline \multicolumn{5}{|l|}{ Statutory medical security } \\
\hline National Health Insurance (ref.) & - & & - & \\
\hline Medical aid type 1 & -0.0055 & $(0.0076)$ & 0.0336 & $(0.0301)$ \\
\hline Medical aid type 2 & 0.0385 & $(0.0238)$ & 0.0014 & $(0.0137)$ \\
\hline Voluntary private health insurance & $-0.0081 * *$ & $(0.0041)$ & 0.0065 & $(0.0040)$ \\
\hline Both parents(-in-law) living together & $-0.0141 * *$ & $(0.0056)$ & $-0.0078 *$ & $(0.0041)$ \\
\hline \multicolumn{5}{|l|}{ Residential area } \\
\hline Metropolitan & - & & - & \\
\hline Small city & -0.0059 & $(0.0046)$ & $-0.0145^{* * *}$ & $(0.0041)$ \\
\hline Rural & -0.0073 & $(0.0064)$ & $-0.0103 *$ & $(0.0058)$ \\
\hline \multicolumn{5}{|l|}{ Survey wave } \\
\hline Wave 1 (ref.) & - & & - & \\
\hline Wave 2 & -0.0027 & $(0.0040)$ & -0.0033 & $(0.0043)$ \\
\hline Wave 3 & -0.0008 & $(0.0059)$ & -0.0025 & $(0.0046)$ \\
\hline Constant & -0.0188 & $(0.0247)$ & 0.0184 & $(0.0182)$ \\
\hline Observations & 2528 & & 4108 & \\
\hline R-squared & 0.5841 & & 0.2151 & \\
\hline Instrumental variable strength ( $F$-statistic) & $86.29 * * *$ & & $36.73 * * *$ & \\
\hline
\end{tabular}

ADL, activity of daily living.

${ }^{\dagger}$ Robust standard errors in parentheses.

$* p<0.1$. $* * p<0.05 . * * * p<0.01$.

estimates on the alternative specification of logged informal care hours do not change qualitatively from the coefficient estimates on the indicator variable of caregiving (Table VI), suggesting the robustness of our results. 


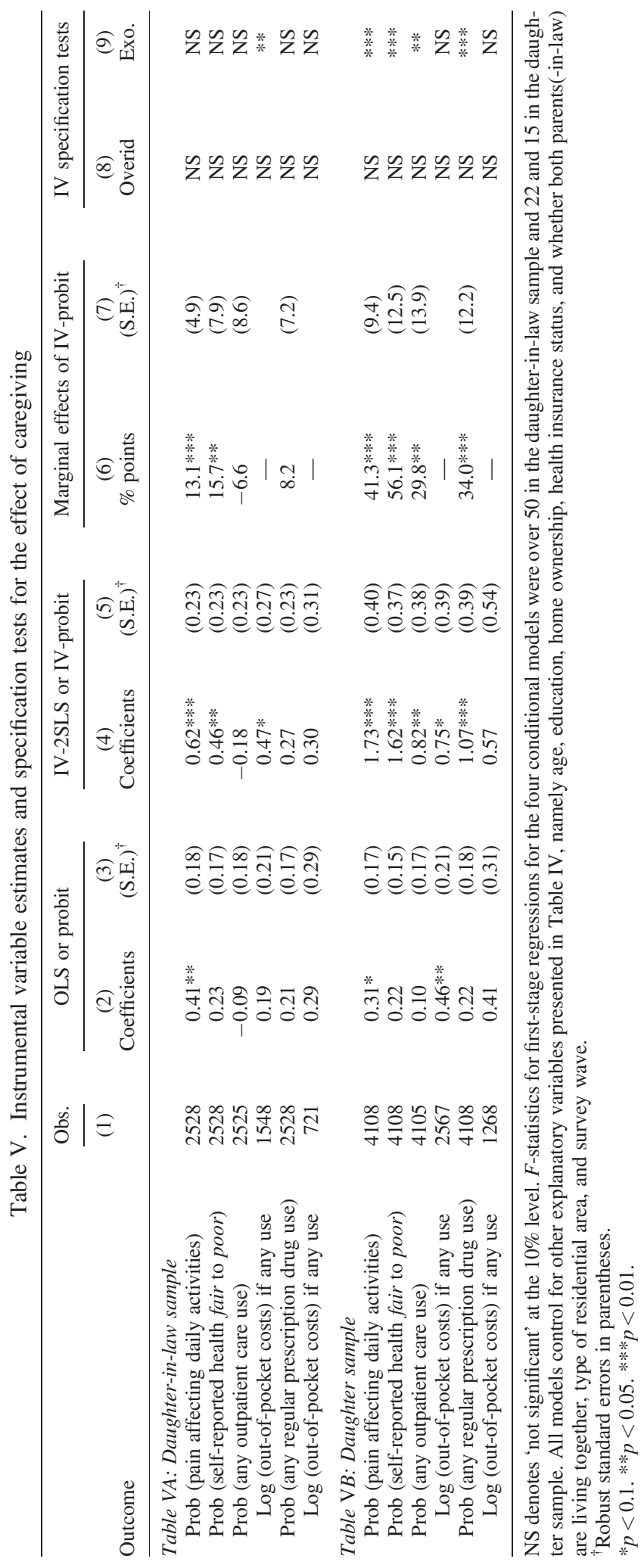




\section{DISCUSSION}

Our results suggest that informal care has adverse health effects along multiple dimensions for daughter-in-law caregivers in South Korea. Our study has carefully tested for the possibility that selection into caregivers by health status might affect the estimation results of caregiver health effects. In doing so, we show that IV estimation can help control for endogeneity, starting with more intuitive Wald estimators.

The main methodological contribution of this paper is that our IV approach solves the problem of endogeneity and allows us to estimate causal parameters. The local average treatment effect interpretation is directly meaningful because the instruments are directly related to why most informal care is provided. Informal care is more likely provided when an elderly family member has more ADL limitations. Finding appropriate instruments has been a problem in this literature, making most of the published results inconclusive about the causal effects of informal caregiving on caregivers' health.

The comparison between daughter-in-law and daughter caregivers in this study provides some insight to the challenge of estimating caregiver health effects. For all outcome measures, the magnitude of the estimated effect was greater in the daughter sample than in the daughter-in-law sample. This may reflect greater negative health consequences among daughter caregivers compared with daughter-in-law caregivers. On the other hand, given that our IV method uses parents' functional limitations as IVs, the IV estimates for daughter caregivers could be inconsistent because of the non-excludability of the IVs (i.e., the family effect itself). Therefore, caution should be taken in interpreting the IV estimates in the daughter sample.

This study has limitations. First, because of the multiple eligibility criteria required for our IV estimation (e.g., currently married women aged 45 years and over with any living parent-in-law) combined with the strict definition of caregiving in the data (i.e., not including co-residential IADL caregiving), our daughter-in-law sample has a modest size with a small number of caregivers, even after three waves of data are combined. One related concern is that our estimates may have been influenced by possible outliers when outcome variables are continuous. Further examining our data, however, excludes this possibility because extreme outliers for the two continuous outcome variables were observed in the comparison group (i.e., non-caregiver) rather than the treatment group (i.e., caregiver). Second, we focus on obtaining valid population-level estimates of the health effects of informal care, and our models do not account for specific caregiving contexts. Our data do not allow for examining contextual factors: whether the care recipient showed problem behaviors often seen in patients with Alzheimer's dementia, how important the caregiver's choice was in the caregiving decision, what the quality of the dyadic relationship between caregiver and care recipient was, what the main type of caregiving tasks was, and whether the caregiver had role conflict. These limitations, of course, apply to all studies that use large national data sets. Although many of these factors may moderate the health effects of caregiving, several

Table VI. Instrumental variable estimates and specification tests for the effect of caregiving hours

\begin{tabular}{|c|c|c|c|c|c|c|c|}
\hline \multirow[b]{2}{*}{ Outcome } & \multirow{2}{*}{$\frac{\text { Obs. }}{(1)}$} & \multicolumn{2}{|c|}{ OLS or probit } & \multicolumn{2}{|c|}{ IV-2SLS or IV-probit } & \multicolumn{2}{|c|}{ IV specification tests } \\
\hline & & $\begin{array}{c}(2) \\
\text { Coefficients }\end{array}$ & $\begin{array}{c}(3) \\
(\text { S.E. })^{\dagger}\end{array}$ & $\begin{array}{c}\text { (4) } \\
\text { Coefficients }\end{array}$ & $\begin{array}{c}(5) \\
(\text { S.E. })^{\dagger}\end{array}$ & $\begin{array}{c}(6) \\
\text { Overid }\end{array}$ & $\begin{array}{l}\text { (7) } \\
\text { Exo. }\end{array}$ \\
\hline \multicolumn{8}{|l|}{ Daughter-in-law sample } \\
\hline Prob (pain affecting daily activities) & 2527 & $0.18^{* *}$ & $(0.08)$ & $0.33 * *$ & $(0.13)$ & NS & NS \\
\hline Prob (self-reported health fair to poor) & 2527 & 0.08 & $(0.08)$ & $0.25 * *$ & $(0.13)$ & NS & $*$ \\
\hline Prob (any outpatient care use) & 2524 & 0.03 & $(0.09)$ & -0.10 & $(0.12)$ & NS & NS \\
\hline Log (out-of-pocket costs) if any use & 1548 & 0.10 & $(0.10)$ & $0.24 *$ & $(0.14)$ & NS & NS \\
\hline Prob (any regular prescription drug use) & 2527 & $0.14 *$ & $(0.08)$ & 0.16 & $(0.12)$ & NS & NS \\
\hline Log (out-of-pocket costs) if any use & 720 & 0.13 & $(0.10)$ & 0.15 & $(0.15)$ & NS & NS \\
\hline
\end{tabular}

NS denotes 'not significant' at the $10 \%$ level. Logarithm of weekly care hours was used. $F$-statistics for first-stage regressions were 26 in the four IV-probit models and 23 and 12 in the two conditional IV-2SLS models. The same set of control variables was used as in Table V. One observation was dropped because of missing value for caregiving hours.

${ }^{\dagger}$ Robust standard errors in parentheses.

$* p<0.1$. ** $p<0.05$. ***p $<0.01$. 
subgroup analyses attempted were limited by small sample sizes even when necessary variables were available. Third, our data do not allow for examining potentially differential effects by phase and duration of caregiving. On the one hand, caregiver health effects can be more pronounced in the earlier phases than later phases. New caregivers may experience numerous changes in their lives and suffer adverse health effects. On the other hand, it is also possible that caregivers who have provided care for an extended period may have poorer health outcomes than new caregivers. The accumulation of longitudinal data would help in accounting for this heterogeneity in future research.

Despite these limitations, we found statistically significant effects of providing informal care on the health of caregivers. In addition to effects on specific measures of health, we found that health care costs of caregivers increased. Thus, given the public financing of health care in South Korea, there are potential tradeoffs between encouraging informal care over long-term care for elders and expending more on the caregiver's health care.

Our study has two policy implications. First, the results support the perspective that informal caregiving is an emerging public health issue (Talley and Crews, 2007). Even though our sample of caregivers was small (due to restrictions on data), our results may apply to a much broader segment of South Korean society. South Korea is now among the fastest aging countries in the world, and the rate of intergenerational co-residence is still relatively high. The number of family caregivers will undoubtedly increase sharply in the decades to come. Our results suggest that caregivers may suffer multiple negative health effects across many domains of physical health.

Second, our results on increased health care costs among informal caregivers suggest that informal caregiving also has direct economic costs that partially offset any savings from lower formal health care costs for elderly. Estimating the costs of informal care has traditionally focused on the opportunity costs of caregivers' time (Arno et al., 1999; Van Houtven and Norton, 2008). Our results, however, suggest that cost-effectiveness analyses related to long-term care policies also need to take into account the health care costs associated with informal caregiving.

\section{CONFLICT OF INTEREST}

The authors declare no conflict of interest.

\section{ACKNOWLEDGEMENTS}

The data for this study were made available by the Korea Labor Institute and Korea Employment Information Service. We thank David Grabowski and other participants at the International Health Economics Association's 8th World Congress on Health Economics and seminar participants at the University of Rochester and Johns Hopkins University for helpful comments. C. H. Van Houtven was supported by the Veterans Affairs Health Services Research and Development Merit Review Program (MRP 05-311).

\section{REFERENCES}

Amirkhanyan AA, Wolf DA. 2003. Caregiver stress and noncaregiver stress: exploring the pathways of psychiatric morbidity. The Gerontologist 43: 817-827.

Amirkhanyan AA, Wolf DA. 2006. Parent care and the stress process: findings from panel data. Journals of Gerontology B: Psychological Science and Social Sciences 61: S248-S255.

Angrist JD, Evans WN. 1998. Children and their parents' labor supply: evidence from exogenous variation in family size. American Economic Review 88: 450-477.

Angrist JD, Imbens GW, Rubin DB. 1996. Identification of causal effects using instrumental variables. Journal of the American Statistical Association 91: 444-455.

Arno PS, Levine C, Memmott MM. 1999. The economic value of informal caregiving. Health Affairs (Project Hope) 18: $182-188$.

Barer BM, Johnson CL. 1990. A critique of the caregiving literature. The Gerontologist 30: 26-29. 
Bobinac A, Van Exel NJA, Rutten FFH, Brouwer WBF. 2010. Caring for and caring about disentangling the caregiving effect and the family effect. Journal of Health Economics 29: 549-556.

Boo K, Chang J. 2006. Korean longitudinal study of ageing: research design for international comparative studies. Survey Research 7: 97-122.

Bookwala J, Yee JL, Schulz R. 2000. Caregiving and detrimental mental and physical health outcomes. In: Williamson GM, Shaffer DR, Parmelee PA (eds). Physical Illness and Depression in Older Adults; A Handbook of Theory, Research, and Practice. Kluwer Academic/Plenum Publishers: New York. 93-131.

Chee YK. 2000. Elder care in Korea: the future is now. Aging International 26: 25-37.

Choi H. 1993. Cultural and noncultural factors as determinants of caregiver burden for the impaired elderly in South Korea. The Gerontologist 33: 8-15.

Coe NB, Van Houtven CH. 2009. Caring for mom and neglecting yourself? The health effects of caring for an elderly parent. Health Economics 18: 991-1010.

Dilworth-Anderson P, Williams IC, Gibson BE. 2002. Issues of race, ethnicity, and culture in caregiving research a 20-year review (1980-2000). The Gerontologist 42: 237-272.

Haley WE, Levine EG, Brown SL, Bartolucci AA. 1987. Stress, appraisal, coping, and social support as predictors of adaptational outcome among dementia caregivers. Psychology and Aging 2: 323-330.

Hsu HC, Shyu YI. 2003. Implicit exchanges in family caregiving for frail elders in Taiwan. Qualitative Health Research 13: 1078-1093.

Imbens GW, Angrist JD. 1994. Identification and estimation of local average treatment effects. Econometrica 62: $467-475$.

Pang KYC. 2000. Symptom expression and somatization among elderly Korean immigrants. Journal of Clinical Geropsychology 6: 199-212.

Pinquart M, Sörensen S. 2003. Differences between caregivers and noncaregivers in psychological health and physical health a meta-analysis. Psychology and Aging 18: 250-267.

Pinquart M, Sörensen S. 2006. Gender differences in caregiver stressors, social resources, and health: an updated meta-analysis. Journals of Gerontology. Series B, Psychological Sciences and Social Sciences 61: 33-45.

Pinquart M, Sörensen S. 2007. Correlates of physical health of informal caregivers a meta-analysis. Journals of Gerontology. Series B, Psychological Sciences and Social Sciences 62: 126-137.

Schulz R. 1990. Theoretical perspectives on caregiving: concepts, variables, and methods. In: Biegel DE, Blum A (eds). Aging and Caregiving: Theory, Research and Policy. Sage Publications: New York. 27-52.

Schulz R, Visintainer P, Williamson GM. 1990. Psychiatric and physical morbidity effects of caregiving. Journal of Gerontology 45: 181-191.

Schulz R, O’Brien AT, Bookwala J, Fleissner K. 1995. Psychiatric and physical morbidity effects of dementia caregiving: prevalence, correlates, and causes. The Gerontologist 35: 771-791.

Sung KT. 1990. A new look at filial piety: ideals and practices of family-centered parent care in Korea. The Gerontologist 30: $610-617$.

Talley RC, Crews JE. 2007. Framing the public health of caregiving. American Journal of Public Health 97: $224-228$.

Van Houtven CH, Norton EC. 2008. Informal care and Medicare expenditures: testing for heterogeneous treatment effects. Journal of Health Economics 27: 134-156.

Vitaliano PP, Zhang J, Scanlan JM. 2003. Is caregiving hazardous to one's physical health? A meta-analysis. Psychological Bulletin 129: 946-972.

Walker AJ, Pratt CC, Eddy L. 1995. Informal caregiving to aging family members a critical review. Family Relations 44: 402-411.

Yamamoto N, Wallhagen MI. 1997. The continuation of family caregiving in Japan. Journal of Health and Social Behavior 38: $164-176$.

Yee JL, Schulz R. 2000. Gender differences in psychiatric morbidity among family caregivers a review and analysis. The Gerontologist 40: 147-164.

Yong F, McCallion P. 2003. Hwabyung as caregiving stress among Korean-American caregivers of a relative with dementia. Journal of Gerontological Social Work 42: 3-19. 